EVS25

Shenzhen, China, Nov 5-9, 2010

\title{
Driver influence in hybrid vehicle economic appraisal
}

\author{
Adriano Alessandrini ${ }^{1}$, Francesco Filippi ${ }^{1}$, Fernando Ortenzi ${ }^{1}$, Fabio Orecchini ${ }^{2}$ \\ ${ }^{1}$ CTL, Sapienza University of Rome, Via Eudossiana 18,00184 Rome, Italy, adriano.alessandrini@unroma1.it \\ ${ }^{2}$ Guglielmo Marconi University - Via Plinio 44 Roma. Italy
}

\begin{abstract}
Hybrids are seen as a potential solution to urban traffic pollution and energy consumption; however studies show how pollution economic appraisal is one order of magnitude lower than fuel cost putting all the burden of the economic success the hybrid capability of reducing fuel consumption.

Two Honda Civic Hybrid of the Italian Ministry of Environment fleet were constantly monitored while driven one each by the calmest and by the most aggressive of the Ministry drivers to assess driver effects on air pollutant emissions.

Measurements have shown how the aggressive driver emits 10 times more VOC, and 4 times more CO and NOx than the calm driver while consuming 35\% more fuel. In the economic appraisal over the expected 14 years vehicle life however the aggressive driver costs $16300 €$ while the aggressive one $22500 €$ only $38 \%$ more. This is due to the extremely low cost of emissions (excluding CO2) which is $160 €$ for the calm driver and $610 €$ for the aggressive one for the entire life of the vehicle.

Unless pollutants are monetized according to the position where they are "left" in the atmosphere there is no way emission differences between cars and drivers can be reflected in any economic appraisal.
\end{abstract}

Keywords-Hybrid vehicles, emissions, on-road acquisition, drive-style, economic appraisal.

\section{Introduction}

Hybrid cars are widely seen as a potential solution to urban traffic pollution and energy consumption; however previous studies, [1] and [2], have shown how pollution economic appraisal is one order of magnitude lower than fuel cost putting all the burden of the economic success of the hybrid on its capability of reducing fuel consumption. This effect is even greater if carbon dioxide reduction is considered as an effect of fuel consumption reduction rather than among the other air pollutants (i.e. nitrogen oxides, carbon monoxide, particulate matters and volatile organic compounds). Any initiative to internalize social costs would therefore not promote hybrid car diffusion as much as small Diesel engines despite hybrid cars can generally achieve lower air pollutant emissions [3].
Furthermore previous studies [3] showed how drivers are responsible, as much as vehicles, of the emissions, and, despite hybrid vehicles tend to pollute generally less than conventional ones, the drivers still can have an influence on the emissions. Driver education to a more "environmental friendly" behavior is therefore as important as lowering vehicle emissions.

Is it possible to educate drivers to pollute less by internalizing the cost of their pollutions? In other words, where vehicles equipped with devices to measure the emissions really produced and drivers asked to pay for the corresponding social cost, would the price to pay be a sufficient incentive to change drive-style?

This paper main objective is to answer to these questions. It was first necessary to assess the extent of driver influence on consumption and emissions of hybrid vehicles and then to make an 
economic appraisal of the driver influence on hybrid vehicles.

To assess the driver influence on hybrid vehicle emissions a data acquisition campaign was organized in cooperation with Honda Italia SpA, who sponsored the research providing the vehicles and the necessary funding, and the Italian Ministry of Environment, who got from Honda Italia two Honda Civic Hybrid to be used in its fleet equipped with CTL tools for driver behavior and vehicle response measurement.

CTL tool to monitor vehicle and driver behavior is described in section 2 of this paper; the acquisition campaign and its results are the subjects of section 3; section 4 deals with the economic appraisal made on the basis of the campaign results; finally section 5 concludes the paper.

The main results obtained are that despite drivestile can increase emissions of the different species from 4 to 10 times the corresponding social costs, due to generally low level of emissions of the tested vehicles and to low social costs of the non-CO2 emissions, is negligible.

Albeit the authors whishes to leave to the expert Economists to decide which is the right monetary value of each pollutant, damages caused by non$\mathrm{CO} 2$ pollutants are very much dependent on where emissions are produced and "left" in the atmosphere. Any monetization of the social costs of such pollutants should reflect the location aspect. New tools allow to precisely geo-reference the emissions produced, in fact data used in this paper are all geo-referenced, and it would be interesting doing again the economic appraisal should the monetary values of each pollutant be made location dependent.

\section{The acquisition tool}

From the first ever directive of 1970 (70/220/EEC), which set the limit values for carbon monoxide and hydrocarbon emissions from petrol vehicles the European Union has regulated the allowed emissions of vehicles circulating in Europe. Among the other tenths of directives the 98/69 CE B (which first introduced the Euro IV) made compulsory for any new vehicle an On Board Diagnostic (OBD) system to allow at any time checking the engine is still working in conformity with the directive.

A number of engine working parameters have to be provided by law through the standard OBD interface.
Since 1998 any car maker, and not only in Europe, have progressively introduced more and more electronics to control engine and braking and vehicle handling. Today any vehicle makes available through the communication and diagnostic system, more or less in a standard form, tents of parameters collectable up to $100 \mathrm{~Hz}$ frequency.

Since its start-up in 2003 CTL, funded by the Italian Ministry of Research as the Italian excellence centre on transport and logistics, has continuously developed an on-board data collection tool for several uses including remote vehicle monitoring.

The general concept of the tool is shown in Figure 1.

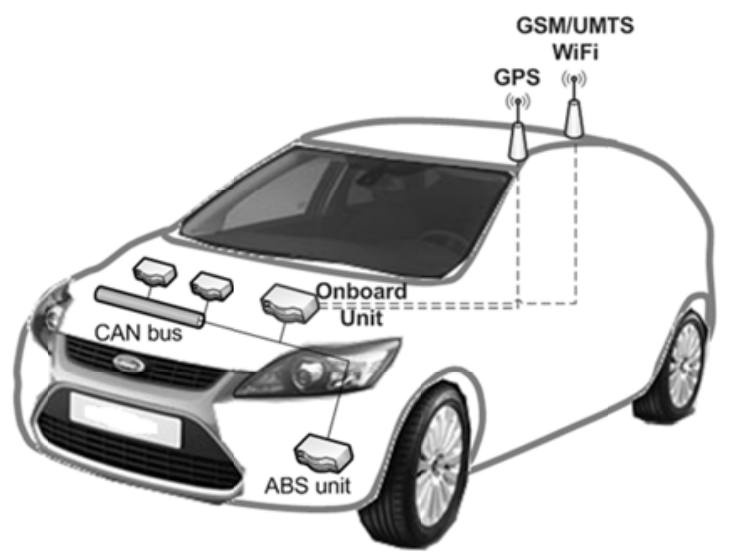

Figure 1 The On Board tool installed on a vehicle.

An on board unit, a common car-pc which switches on with the vehicle and switches of after 15 minutes the vehicle has been switched off, is connected through the $\mathrm{OBD}$ port to the vehicle electronic system (most commonly a CAN bus) and communicates with all the control units of the vehicles (most important ones are the ECU for the engine and the ABS for brakes and vehicle dynamics). The on board unit collect a number of parameters with frequencies up to $4 \mathrm{~Hz}$, depending on their dynamic, and store them in a database. As soon as a Wi-Fi connection is available the database of acquired data is transferred to the CTL servers. The UMTS connection is used to signal emergencies (e.g. low oil pressure, high engine coolant temperature, ...) or to transfer the data at the end of the day in case the vehicle had not encountered any Wi-Fi connection during the day.

The data collected, their treatment and a thorough validation process to prove the data are reliable are reported in [4]. The Honda Civic Hybrid makes available a number of interesting 
parameters: vehicle speed, air/fuel ratio (collected with a wide band sensor and therefore precise from 9 to 30), the intake airflow, engine angular velocity (RPM), engine load, accelerator pedal position, lambda sensor voltage, catalyst temperature, Close/Open Loop information, absolute load (volumetric efficiency), intake air pressure, ignition advance and other. A snapshot of the acquisition software interface with the full list of the data (right hand side of the figure) collected from a Honda Civic Hybrid is provided in Figure 2.

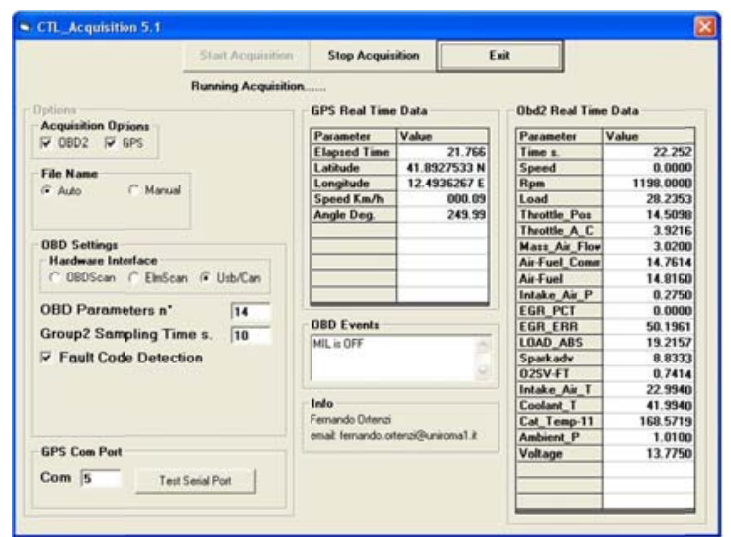

Figure 2 Screenshot of the acquisition software to collect the engine parameters from the OBD connector of the Honda Hybrid.

With respect to the tool described in [4] and used in [3] to compare hybrid and conventional vehicles a great improvement has been made for this study. The vehicle instantaneous emissions are directly dependent on the engine working conditions which are very precisely collected by the tool. Models have therefore been developed to link any engine working conditions to the emissions produced. The developed models for the Honda Civic Hybrid are reported in [5] and have been proven to measure emission better than portable emission measurement tools at the chassis dynamometer at the Engine Institute (Istituto Motori) of the Italian National Research Counsel (CNR) in Naples. The tool now offers one great advantage the for this analysis: it is completely automatic and invisible to the driver who, ignoring to be monitored, drives naturally.

$\mathrm{CO}_{2}$ and $\mathrm{CO}$ are calculated using a chemical equilibrium combustion model with 6 combustion products, with the equilibrium temperature used as a calibration constant. VOC and $\mathrm{NO}_{\mathrm{x}}$ are produced by the Honda Hybrid only in cold start (when they depend on the catalyst temperature) and during engine transients when they have been proven to be dependent on the accelerator pedal gradient.

To validate the models three different Honda Civic Hybrid have been tested on the chassis dynamometer on several driving cycles including the three Artemis driving cycles which better than any synthetic driving cycles represent real world driving (RWDB) [6] and [7]. The emissions have been measured with the CVS (taken as reference) and with a portable emission analyzer, (Horiba OBS 1300), used for comparison with the models. The results, Figure 3, show how the values calculated by the models for $\mathrm{CO} 2, \mathrm{CO}, \mathrm{VOC}$ and $\mathrm{NO}_{\mathrm{x}}$ are as or more accurate than those measured by the OBS [5].

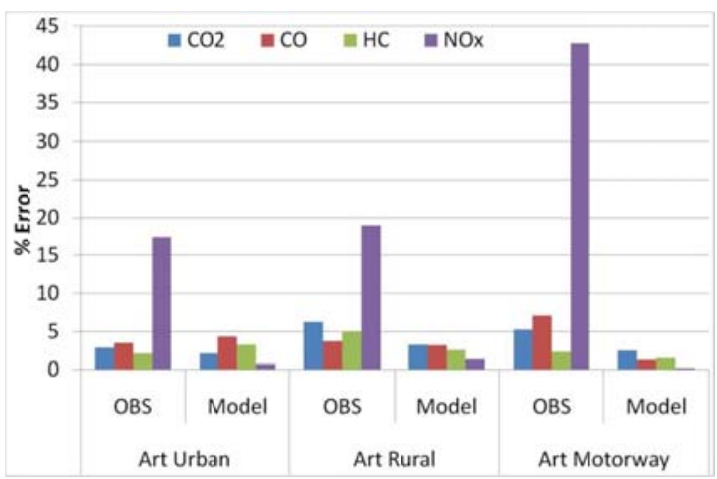

Figure 3 Comparison of errors between an onboard measurement system and the models respect to the CVS.

Errors shown in Figure 3 are calculated with respect to the aggregate measure given by the CVS and normalized, with the exception of the $\mathrm{CO}_{2}$, with respect to the Euro IV limits (the directive to which the vehicle respond) as in equation 1 for $\mathrm{CO}$.

$$
E r r \%_{C O}=\frac{C O_{\text {Model }, \text { OBS }}-C O_{C V S}}{C O_{\text {EuroIV }}}
$$

This formula was used because the emissions values were very low so the EURO IV limits were used as an end scale reference.

\section{The acquisition campaign}

Since October 2006, when Honda released in Italy the Honda Civic Hybrid, Honda Italia SpA has undertaken a number of initiatives to promote its hybrid vehicles. Rather than classical marketing and publicity actions Honda Italia invested in independent research studies to quantify the real energy-environmental performances of its hybrids especially in comparison with conventional vehicles. 
In this framework Honda Italia $\mathrm{SpA}$ has funded three subsequent CTL researches on its hybrids. The first to adapt CTL tools to hybrid vehicles; the second [3] to compare the performances of three Honda Civic, the Hybrid, the older hybrid named IMA and a conventional $2000 \mathrm{cc} 16 \mathrm{v}$; the third one to extend the results of the second, obtained monitoring a sample of drivers doing a given route with the three cars, to professional drivers unaware to be monitored.

The campaign described in this section is the one organized for the third of the Honda-CTL researches.

Honda Italia provided two identical Honda Hybrid to the Italian Ministry of Environment. The Ministry used them in its fleet of "service cars". The cars were first given to CTL, in October 2007 , to be thoroughly tested on the chassis dynamometer, to check they had exactly the same energy-environmental response, and to be equipped with the latest version of CTL tool to be hidden on board from the drivers.

The Ministry received the cars at the end of October and selected two drivers considered the most aggressive, a young man in his mid twenties, and the calmest, a fifty year old man. Cars and drivers were automatically monitored in November and December 2007 while used exactly as the two drivers were used to use the cars they drove previously.

In two months the cars had an overall recorded millage of $3600 \mathrm{~km}$ subdivided in 173 sessions (each being the data collected from one switch on and off of the vehicle).

The aggregate results of the campaign show average emissions of:

- $\mathrm{CO} 2$ of $144 \mathrm{~g} / \mathrm{km}$,

- $\mathrm{CO}$ of $0.83 \mathrm{~g} / \mathrm{km}$,

- VOC of $0.01 \mathrm{~g} / \mathrm{km}$ and

- NOx of $0.0035 \mathrm{~g} / \mathrm{km}$.

All these values are all below both EURO IV and EURO V limits with NOx and VOC one order of magnitude below the limit. The measured average fuel consumption is $13,8 \mathrm{~km} / 1(7,21 / 100 \mathrm{~km})$.

When the same results are split according to the driver (table 1) the calmer emits on average 130 $\mathrm{g} / \mathrm{km}$ of $\mathrm{CO} 2$ against $166 \mathrm{~g} / \mathrm{km}$ of the more aggressive (28\% less) and consumes $6.58 \mathrm{1} / 100 \mathrm{~km}$ of fuel against $9.09 \mathrm{l} / 100 \mathrm{~km}$ (38\% less).

Differences on the other emissions are even more pronounced 4 times for $\mathrm{CO}$ and NOx and 10 times for VOC (table 1 again).

All these differences in emissions and consumptions do not reflect in the average speed which is even slightly higher in average for the calm driver than for the aggressive one.

Table 1: Average emissions, consumption and speed for the two drivers

\begin{tabular}{|c|c|c|}
\hline \multirow{2}{*}{} & \multicolumn{2}{|c|}{ Drivers } \\
\cline { 2 - 3 } & Calm & Aggressive \\
\hline $\mathrm{CO}_{2} \mathrm{~g} / \mathrm{km}$ & 130 & 166 \\
\hline $\mathrm{CO} \mathrm{g} / \mathrm{km}$ & 0.37 & 1.38 \\
\hline $\mathrm{VOC} \mathrm{g} / \mathrm{km}$ & 0.002 & 0.018 \\
\hline $\mathrm{NOx} \mathrm{g/km}$ & 0.004 & 0.014 \\
\hline Average speed km/h & 39.4 & 37.7 \\
\hline Consumption 1/100km & 6.58 & 9.09 \\
\hline
\end{tabular}

To check whether these difference varied with the route chosen the emission of the two vehicles have been analyzed according to the road segment on which they were produced. Such analysis showed how differences are higher on urban roads, where average speeds are low; while the more the average speed grows the less difference between driver-emissions exist.

Figure 4 is a snapshot of CTL web interface for data analysis. It has a map of Rome. Few road links, on which vehicles passed several times each, are highlighted in red. Clicking on one highlighted link the "call out" window with the chart pops up. The chart in the popped up window in Figure 4 shows on "via del Circo Massimo" the dependence of $\mathrm{CO}$ emissions from one aggregate indicator of the driver behavior: the standard deviation of the accelerator pedal position. Each dot in the figure is one passage of one vehicle/driver on via del Circo Massimo. The dot is green for the aggressive driver and red for the calm one. The more the driver moves the accelerator pedal, passing suddenly from zero $(0 \%)$ to full throttle $(! 00 \%)$ and vice versa the more the standard deviation grows. The calm driver arrives maximum to $28 \%$ on the link wile the aggressive driver reaches $45 \%$. On the vertical axes there are the $\mathrm{CO}$ emissions in $\mathrm{g} / \mathrm{km}$. The red dots are almost always on the bottom line between 0 and $2 \mathrm{~g} / \mathrm{km}(1 \mathrm{~g} / \mathrm{km}$ is the Euro IV limit) while the green dots goes up to $20 \mathrm{~g} / \mathrm{km}$. 


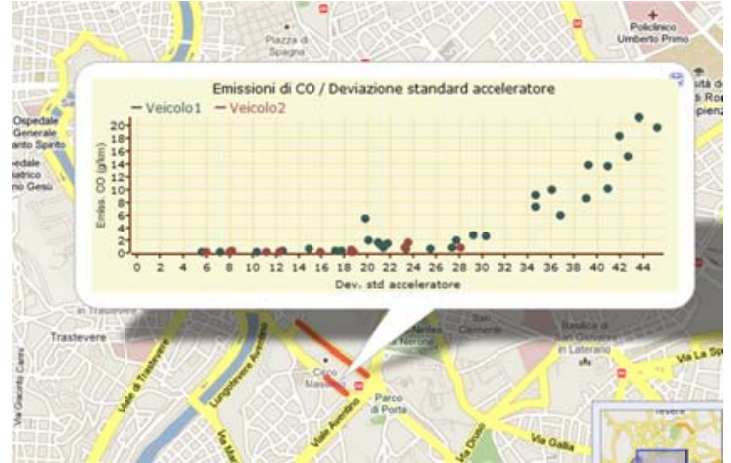

Figure 4 Snapshot of the web interface showing CO emissions on "via del Circo Massimo" for the two drivers (veicolo 1 for the aggressive and veicolo 2 for the calm) as a function of the accelerator pedal standard deviation. Each dot is a passage on the road.

Via del Circo Massimo is well chosen to show huge differences between the drivers. It starts with about 200 meters of straight road, uphill with little traffic just after a traffic light; any aggressive driver there goes at full throttle. Around the middle it reaches the top of the hill had has a large roundabout where it is necessary to slow down and then a downhill segment with uneven pavement and a major traffic light at the end where almost always a stop is necessary. There are no major differences on the average speed but big differences in the speed reached in the first part of the road link where most of the emissions are produced.

However, even choosing different road links, larger emission differences than the averages of table 1 can occur locally between driver.

\section{The economic appraisal}

To measure the economic impact of driver behavior over the vehicle life, excluding any possible effect on congestion, road safety or vehicle maintenance, the monetary values of the emissions produced have been added to the costs of fuel.

To calculate the overall costs of fuel and emissions an overall mileage of over $250000 \mathrm{~km}$ in 14 years was estimated as vehicle lifetime.

The average values of consumption and emissions per kilometer reporter in table 1 have been multiplied by the $250000 \mathrm{~km}$ to have the overall fuel consumed and emission produced by the two vehicles in the 14 of expected life-time.

The cost of fuel has been considered to be constantly $1.4 € l$ as it was on average in Italy on the second of august 2010.
Table 2: the social costs of emissions calculated by two sources, one international and one Italian

\begin{tabular}{|c|c|c|}
\hline \multirow{2}{*}{$\begin{array}{c}\text { Emission Social } \\
\text { Costs } € \text { t }\end{array}$} & \multicolumn{2}{|c|}{ Costs of the different sources } \\
\cline { 2 - 3 } & {$[5]$} & {$[8]$} \\
\hline CO2 & 25 & 85.69 \\
\hline CO & 0 & 1477.89 \\
\hline VOC & 1100 & 8018.88 \\
\hline NOx & 5700 & 19087.68 \\
\hline
\end{tabular}

Literature reports very different values for the costs of emissions. The two most accredited, respectively internationally and in Italy have been selected for the purpose of this study.

The prices of the different emission species by the two sources are reported in table 2 .

The international Handbook [8] and the Italian NAMEA [9] seem to have different magnitudes for the social costs of the emissions, between 3 and 7 times lower for the Handbook [8]. Furthermore the Handbook [8] does not consider $\mathrm{CO}$ worth anything while for NAMEA [9] it costs over 1.4 thousand Euros per ton. Such position on $\mathrm{CO}$ seems not completely coherent with the chemical process. Each mole of $\mathrm{CO}$ will, in the end, transform in one mole of $\mathrm{CO} 2$. From the 28 grams of the $\mathrm{CO}$ mole the $\mathrm{CO} 2$ will weight 44 grams; therefore $\mathrm{CO}$ emissions should at least cost $39 € / \mathrm{t}$ in proportion to the $\mathrm{CO} 2$ costs and the difference in weight.

Table 3 is obtained applying the social costs provided by the Handbook [8] (first column of table 2) to the results of the measurements for the two drivers (table 1 of previous section) over the $250000 \mathrm{~km}$ of expected vehicle life.

Excluding $\mathrm{CO} 2$ the total amount of social costs for emissions in the 14 years is $6.3 €$. On the other hand the non-CO2 emissions would cost to the aggressive driver more than 4 times that but still the negligible sum of 25 Euros. Including $\mathrm{CO} 2$ the overall costs rise up to $818.8 €$ for the calm and $1062.5 €$ for the aggressive both negligible with respect to the cost of fuel respectively 15471.3 for the calm driver and 21378.6 for the aggressive.

Applying the Handbook [8] social costs the costs of emissions are entirely negligible. The internalization of social costts would just be about $\mathrm{CO} 2$ and could be easily done by increasing the fuel cost of about $5 \%$. 
Table 3: External costs for the two drivers according to the Handbook [8]

\begin{tabular}{|c|c|c|}
\hline \multirow{2}{*}{$\begin{array}{c}\text { Total Costs } \\
\text { according to } \\
\text { source [8] }\end{array}$} & Calm & Aggressive \\
\cline { 2 - 3 } & 812.5 & 1037.5 \\
\hline CO2 & 0 & 0 \\
\hline CO & 0.6 & 5.0 \\
\hline VOC & 5.7 & 20.0 \\
\hline NOx & 818.8 & 1062.5 \\
\hline $\begin{array}{c}\text { Total cost for } \\
\text { emissions }\end{array}$ & 15471.3 & 21378.6 \\
\hline Consumption & 16290.1 & 22441.1 \\
\hline Total cost & & \\
\hline
\end{tabular}

Table 4: External costs for the two drivers according to NAMEA cost tables [9]

\begin{tabular}{|c|c|c|}
\hline \multirow{2}{*}{$\begin{array}{c}\text { Total Costs } \\
\text { according to source } \\
{[8]}\end{array}$} & \multicolumn{2}{|c|}{$\begin{array}{c}\text { Costs for the different } \\
\text { drivers }\end{array}$} \\
\cline { 2 - 3 } & Calm & Aggressive \\
\hline CO2 & 2784.9 & 3556.1 \\
\hline CO & 136.7 & 509.9 \\
\hline VOC & 4.0 & 36.1 \\
\hline NOx & 19.1 & 66.8 \\
\hline $\begin{array}{c}\text { Total cost for } \\
\text { emissions }\end{array}$ & 2944.7 & 4168.9 \\
\hline Consumption & 15471.3 & 21378.6 \\
\hline Total cost & 18416.0 & 25547.5 \\
\hline
\end{tabular}

Table 4 is obtained repeating the same calculations with the NAMEA [9] social costs.

Beside $\mathrm{CO} 2$, VOC and NOx costs being all from 3 to 7 times higher the main difference between the costs in table 3 and 4 is the $\mathrm{CO}$. The social cost for non $\mathrm{CO} 2$ emissions for the aggressive driver were in table $325 €$. In table 4 they are $612.8 €$. The main difference is in the nearly $510 €$ for $\mathrm{CO}$ which was completely neglected in table 3 .

Overall the emissions costs for the calm driver rise from 800 to $2900 €$ and for the aggressive from $1000 €$ to $4100 €$. Still the main cost is CO2, which is linked to consumption more than anything else.

Even considering the higher NAMEA [9] values to calculate the social costs the overall cost difference between an aggressive and a calm driver is only $38 \%$ despite the aggressive driver emits 10 times more VOC, and 4 times more $\mathrm{CO}$ and NOx than the calm driver while consuming $35 \%$ more.

\section{Conclusions}

Hybrid cars have proven to be able to contain noxious emissions (all but $\mathrm{CO} 2$ which depends mainly on fuel consumption) while being in the same league of conventional Diesel cars in terms of fuel consumption.

Previous studies had shown how internalizing the external costs of vehicle-pollution was not enough to justify the extra cost of an hybrid vehicle mostly because the main social cost is due to the monetization of $\mathrm{CO} 2$.

Despite the good results of the hybrid technology to minimize noxious emissions however drivers still have an influence on the emissions produced.

The aim of this paper was to assess whether the technique of internalizing the social costs of emissions could be used to foster a more "environmental friendly" behavior on the drivers. Two identical Honda Civic Hybrid were equipped with CTL tool to monitor driver behavior and vehicle response to it and given to two professional drivers of the Italian Ministry of Environment selected because they are the calmest and the most aggressive drivers in the Ministry service. The drivers were unaware to be monitored and therefore behaved normally.

The vehicles were monitored for two months and had an overall mileage of $3600 \mathrm{~km}$.

As overall result the car were able to keep all emissions under the EURO IV and EURO V limits but when the same results are split according to the driver the calmer emits on average $130 \mathrm{~g} / \mathrm{km}$ of CO 2 against $166 \mathrm{~g} / \mathrm{km}$ of the more aggressive (28\% less) and consumes $6.58 \mathrm{l} / 100 \mathrm{~km}$ of fuel against $9.091 / 100 \mathrm{~km}(38 \%$ less).

Differences on the other emissions are even more pronounced 4 times for $\mathrm{CO}$ and $\mathrm{NOx}$ and 10 times for VOC.

All these differences in emissions and consumptions do not reflect in the average speed which is even slightly higher in average for the calm driver than for the aggressive one.

When analyzing the data on single road links differences are even greater; the aggressive driver can emit 20 times more $\mathrm{CO}$ than the calm one.

Despite these results in the economic appraisal over $250000 \mathrm{~km}$ in 14 years estimated vehicle lifetime the calm driver costs between $16300 €$ and $18400 €$ (depending on the social costs used to monetize emissions) while the aggressive one costs between $22500 €$ and $25500 €$ only $38 \%$ more. This is due to the extremely low cost of emissions (excluding $\mathrm{CO} 2$ ) which is maximum 
$160 €$ for the calm driver and maximum $610 €$ for the aggressive one for the entire life of the vehicle.

However in the economic appraisal the emissions are monetized with an average value which does not account where it has really been produced. This is correct for $\mathrm{CO} 2$ which is causing only global warming effects but not for the other pollutants which have a direct effect on the people inhaling them and on the damages on cultural heritage.

Overall an aggressive driver can emit several times more than a calm one even driving a hybrid vehicle but unless pollutant are monetized according to the position where they are "left" in the atmosphere there is no way these differences can be reflected in any economic appraisal and driver differences, as well as vehicle differences, in terms of pollutant emissions will be set aside with respect to fuel consumption.

\section{References}

[1] Lave L.B., H.L. MacLean, An environmentaleconomic evaluation of hybrid electric vehicles: Toyota Prius vs. its conventional internal combustion engine Corolla, Trasportation Research Part D 7 (2002) 155162

[2] Alessandrini A., F. Filippi, F. Ortenzi, Hybrid Vehicle Sustainability Evaluation: The Honda Hybrid Case, Jubilary Workshop: 30 Years AFHB, 20 Years Collaboration BAFU / AFHB,3 April 2009, Bern

[3] Alessandrini A., F. Orecchini, F.Ortenzi, F.Villatico Campbell, Drive-style emission testing on conventional and hybrid vehicles to measure real road transport emissions, European Transport Research Review: Volume 1, Issue2 (2009), Page 57-66 ISSN 1867-0717 (Print) 1866-8887 (Online)

[4] A. Alessandrini, F.Filippi, F. Orecchini, F.Ortenzi, A new method for collecting vehicle behaviour in daily use for energy and environmental analysis, JAUTO165 (C) IMechE 2006 Vol. 220 Part D: J. Automobile Engineering pages 1527-1537

[5] F.Ortenzi, M.A.Costagliola, A new method to calculate instantaneous vehicle emissions using OBD data, SAE 2010 World Congress, April 12-15, 2010, Detroit, Michigan, USA, SAE Paper 2010-01-1289
[6] André, M., 2004, The ARTEMIS European driving cycles for measuring car pollutant emissions. Science of the Total Environment 334-335, pp.73-84;

[7] André, M., Jourmard, R., Vidon, R., Tassel, P., Perret, P., 2006, Real-world European driving cycles, for measuring pollutant emissions from high- and low-powered cars. Atmospheric Environment 40,pp.5944-5953

[8] M. Maibach, C. Schreyer, D. Sutter H.P. van Essen, B.H. Boon, R. Smokers, A. Schroten C. Doll B. Pawlowska and M. Bak Handbook on estimation of external costs in the transport sector Produced within the study Internalisation Measures and Policies for All external Cost of Transport (IMPACT) Version 1.12008 downloadable at http://ec.europa.eu/transport/sustainable/doc/20 $\underline{08 \text { costs_handbook.pdf }}$

[9] Istat NAMEA Costi economici nazionali $e$ ambientali 1990-2003 Direzione Centrale della Contabilità Nazionale, Contabilità Ambientale. www.istat.it 2007

\section{Authors}

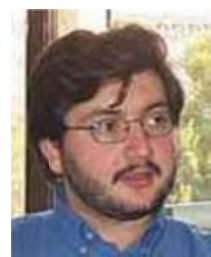

\section{Dr. Adriano Alessandrini}

CTL - Sapienza Università di Roma, Via Eudossiana 18, I-00184 Rome, Italy

Tel. 39-06-44585148

Mechanical engineer since 1998 and $\mathrm{Ph} . \mathrm{D}$. in energy technologies since 2003 Adriano is currently Research Fellow at CTL to which he participated since the proposal stage to be funded as the Italian centre of excellence on transport and logistics.

Since his graduation he has participated and conducted European research projects on transport systems and on the environmental impact of transport, his main research fiields.

He speaks fluently Italian, English and French.

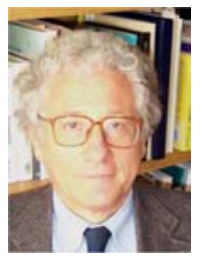

Prof. Francesco Filippi

CTL - Sapienza Università di Roma, Via Eudossiana 18, I-00184 Rome, Italy Tel. 39-06-44585147

francesco.filippi@uniroma1.it Transport engineer since 1970.

Professor in DITS, Engineering Faculty, University 
of Rome La Sapienza. He is the founding director of CTL. He has been active, since the 3rd Framework Programme in European research.

Numerous papers published in Europe and the U.S.; on Editorial Advisory Board of Transportation Research. Languages: Italian, English, French, Portuguese.

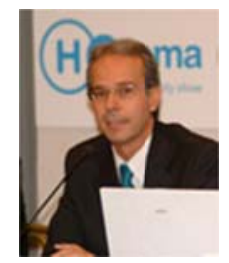

\section{Prof. Fabio Orecchini}

Professor at Guglielmo Marconi University -. Via Plinio 44 Roma

Co-ordinator of "Energy and environment Research Group"-GEA at CIRPS - Interuniversity research centre for sustainable development and "Automotive Research Group", GRA at "Sapienza" University of Rome. Scientific coordinator of national and international research projects. RESEARCH TOPICS

Sustainability of Energy systems; Renewable energy resources and technologies; Hydrogen energy chain; Renewables to Hydrogen; Energy systems and solutions for Sustainable Mobility.

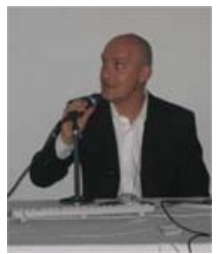

Dr. Fernando Ortenzi

CTL - Sapienza Università di Roma, Via Eudossiana 18, I-00184 Rome,

Italy

Tel. 39-06-44585148

Fernando Ortenzi is a mechanical

technologies. engineer and Ph.D in energy

$\mathrm{He}$ is a research fellow at CTL. His main research interests are: the measurement of energy and environmental impact of vehicles and the development of tools to collect data from the electronic system of vehicles and trucks for emission modelling and fleet management. 